\title{
STUDY ON NEUROMUSCULAR MANIFESTATIONS IN PATIENTS WITH DIABETES MELLITUS - A STUDY OF 100 CASES
}

\author{
SARDAR MH ${ }^{1}$, HOSSAIN MM², HOSSAIN MZ ${ }^{3}$, BARI A ${ }^{4}$
}

\begin{abstract}
:
Background: There are common, important and various types of relationships between DM and NMM. The aim of this study was to find out patterns of NMM in diabetic patients and to find out a strategy to improve the outcome of the neuromuscular (NM) complications in patient with Diabetes Mellitus.

Methods: The results were based on hospital based observational data from 100 consecutive patients, both men and women (aged e"14 to 70 years) with diabetes with neuro-muscular (NM) manifestations. Patients were assessed by a meticulous history, relevant general and systemic examination and with the aid of NM Function Assessment, appropriate investigations and semi structured questionnaire. This study was done in Dhaka Medical College Hospital, Dhaka, from January to June of 2013.

Results: Neuromuscular disorders are a common finding among patients with both type 1 and type 2 diabetes mellitus but more common in type 2. DM was associated with some of NMM. Among the 100 diabetic patients who were screened, exhibit neuromuscular abnormalities, mainly various types of peripheral neuropathies and muscular abnormalities, like diabetic muscular infarction and diabetic amyotrophy. The association between widespread NMMs and $D M$ was most evident among the group of individuals aged around 50 years with type 2 DM.

Conclusion: In this hospital based observational study, NM abnormalities, mainly of the sensory-motor type of peripheral neuropathy and few cases of muscular abnormalities are found. The information thus gathered may provide useful guidelines for diabetic patients with neuromuscular manifestations \&thus sufferings of the patients can be reduced.
\end{abstract}

Key words: DM-Diabetes mellitus; NMM- Neuromuscular manifestations.

J Dhaka Med Coll. 2014; 23(1) : 84-88.

\section{Introduction}

Endocrine disorders commonly cause neuromuscular symptoms and may even present with neuromuscular syndromes before the nature of the underlying endocrinopathy is apparent. Patients with either type 1 or type 2 diabetes mellitus frequently have neuromuscular complaints.

Although there are various hypothesis regarding the pathophysiologic effects of hyperglycemia on nerves and muscles are proposed, there are well-established associations between diabetes and certain neuromuscular syndromes ${ }^{1}$. Diabetes has major effects on myelin and axon of nerves and muscels, which have significant impact on both the development and outcome of these diseases of nerves and muscles. A variety of neuromuscular disorders are associated with diabetes. These disorders may cause pain and functional impairment, and inûuence the ability of patients to adhere to other aspects of diabetes treatment, particularly exercise and weight management ${ }^{3}$.

Diabetes mellitus is a chronic metabolic condition characterized by persistent hyperglycaemia with resultant morbidity and mortality related primarily to its associated

1. Dr. Md. Hafiz Sardar, Associate Professor, Deaprtment of Medicine, Dhaka Medical College, Dhaka.

2. Dr. Mohammad Murad Hossain, Assistant Professor, Department of Medicine, Dhaka Medical College, Dhaka.

3. Dr. Mohammad Zaid Hossain, Associate Professor of Medicine, Dhaka Medical College, Dhaka

4. Dr. Anwarul Bari, Assistant Professor of Medicine, Sir Salimullah Medical College, Dhaka

Correspondence : Dr.Md. Hafiz Sardar, Associate Professor, Department of Medicine, Dhaka Medical College, Dhaka. Cell Phone: +8801712269294, E-mail: drhafizsardar@yahoo.com 
microvascular and macrovascular complications $^{5}$. The precise etiology of most of these neuromuscular disorders is not clear, neither is the reason for their higher prevalence in diabetes ${ }^{4}$. Poor glycaemic control is associated with increased prevalence of these diabetic complications ${ }^{6}$. Examples of common neuromuscular disorders includesensory polyneuropathy, motor polyneuropathy, mononeuropathy, autonomic neuropathy, diabetic muscular infarction and diabetic amyotrophy and reflex sympathetic dystrophy ${ }^{7}$.

Sarkar et al in a cross sectional study compared neurological, muscular and rheumatic manifestations in a cohort of diabetic patients with a group of patients attending a rheumatology clinic of a medical college ${ }^{8}$. Some studies have indeed compared the prevalence of certain manifestations in diabetics such as diabetic muscular infarction and diabetic amyotrophy and reflex sympathetic dystrophy with that of rheumatic controls ${ }^{9}$.

Neuromuscular complaints (NMCs) are among the major health problems worldwide and the most frequent cause of long term sickness leave in Norway ${ }^{10,11}$. Increased mortality has been reported among individuals with chronic widespread neuromuscular complaints ${ }^{12}$. In spite of much improvement of medical sciences, pathogenesis \& pathology of this disease is seldom understood $\&$ management still tends to be based on pragmatism \& prejudice rather than logical scientific regimens ${ }^{13}$. Physical activity is an attractive treatment for patients with diabetes given its low cost, non-pharmacological nature and additional aerobic and cardiovascular beneûts. Exercise is considered to be one of the three cornerstones of optimal diabetes treatment, along with diet and pharmacotherapy 14. A recent meta-analysis has shown that exercise training in patients with type 2 diabetes mellitus reduces $\mathrm{HbA} 1 \mathrm{C}$ by an amount that should decrease the risk of diabetic complications. This was not associated with an appreciably greater change in body mass in the intervention group compared with the control group suggesting that exercise training in patients with type 2 diabetes is valuable in its own right rather than being just an avenue to weight loss. Physical activity is therefore an attractive treatment for patients with diabetes given its low cost, non- pharmacological nature, and additional aerobic and cardiovascular beneûts. Sports physicians and patients with diabetes should be aware of these manifestations, so that optimal physiotherapy programmes can be devised that do not exacerbate existing complaints and encourage continuing physical activity in this group ${ }^{15}$.

In this study an attempt has been made to find out pattern of NM complications among the diabetic patients admitted into Dhaka Medical College Hospital. The information thus gathered may provide useful guidelines for diabetic patients with neuromuscular manifestations \& sufferings of the patients can be reduced. So they may contribute themselves for the prosperity of the country.

Suggested classification of $\mathbf{n m}$ manifestations Several neuromuscular disorders have been described in these patients which can be ${ }^{16}$ :

a. Consequences of diabetic complications

b. Consequences of metabolic derangements inherent to diabetes

c. Syndromes that may share etiologic mechanisms with microvascular disease

d. Probable association.

Consequences of diabetic complications

- Polyneuropathy

- Diabetic muscular infarction

- Diabetic amyotrophy

Probable association

- Osteoarthritis,

- Gout,

- Carpal tunnel syndrome

\section{Methods}

All diabetic patients with neuromuscular manifestations are included in this study. A meticulous history, general and systemic examinations have been done. All relevant tests have done. Informed and written consent have taken from all patients. After informed consent, they have been included in the study. This hospital based observational study with 
descriptive and analytic components, on 100 consecutive patients with diabetes with neuromuscular manifestations admitted into Dhaka Medical College Hospital, Dhaka, for six months, from January to June 2013.

\section{Inclusion criteria:}

1. Patients with the history of DM with neuromuscular features

2. Age 14-70 years.

Exclusion criteria:

1. Without mentioned $1 \& 2$ of inclusion criteria.

2. Patients known to have rheumatologic disease as RA, SLE, Malignancy, alcoholic liver disease

3. Patients with the history of DM with neuromuscular feature but requiring surgical intervention

4. Patients did not agree

\section{Results:}

During the period of six months a total number of 100 consecutive diabetic patients with neuromuscular manifestations were studied. Out of 100 patients in my study $72(72 \%)$ were Male and $28(28 \%)$ were female giving as male female ratio 2.57:1. Age distribution of study patients were 14 to 70 years. Maximum numbers of the patients were in the age group of 40 to 59 years $(72 \%)$. Overall $76 \%$ of patients were $<30$ years and $24 \%$ were $>30 y e a r s$ and above.

Table 1.1

Distribution of the patient in relation to sex showing maximum number of patients in this study were male (72\%) \& female (28\%) $(n=100)$

\begin{tabular}{lcc}
\hline Gender & Frequency & Percent $(\%)$ \\
\hline Female & 28 & 28 \\
Male & 72 & 72 \\
Total & 100 & 100 \\
\hline
\end{tabular}

Table 1.2

Distribution of the patients in age categories $(n=100)$

\begin{tabular}{lcc}
\hline Age (in years) & No. of patients & Percentage \\
\hline $14-39$ & 08 & $8 \%$ \\
$40-59$ & 72 & $72 \%$ \\
$60-70$ & 20 & $20 \%$ \\
\hline
\end{tabular}

Table 1.3

Occupational distribution of the patients with musculoskeletal manifestations ( $n=100)$

\begin{tabular}{lcc}
\hline Occupation & $\begin{array}{c}\text { Number of } \\
\text { patients }\end{array}$ & $\begin{array}{c}\text { Percentage } \\
(\%)\end{array}$ \\
\hline Service & 16 & 16.0 \\
Business & 14 & 14.0 \\
Labour & 06 & 6.0 \\
Cultivator & 14 & 14.0 \\
Housewife & 28 & 28.0 \\
Unemployed & 20 & 20.0 \\
Other & 02 & 2.0 \\
\hline Total & 100 & 100.0 \\
\hline
\end{tabular}

$\mathrm{n}$ : number of patients

The above table shows that the majority patients were Housewife (28\%). Other were business (14\%), Service (16\%).Unemployed $(20 \%)$ and cultivator $(14 \%)$.

Table 1.4

Distribution of individual NM abnormalities in patients with DM $(n=100)$

\begin{tabular}{lcc}
\hline $\begin{array}{l}\text { Individual NM } \\
\text { abnormalities }\end{array}$ & $\begin{array}{c}\text { Number of } \\
\text { patients }\end{array}$ & $\begin{array}{c}\text { Percentage } \\
(\%)\end{array}$ \\
\hline Sensory polyneuropathy & 48 & 48 \\
Motor polyneuropathy & 20 & 20 \\
Mononeuropathy & 18 & 18 \\
Autonomic neuropathy & 06 & 06 \\
Neuropathic ulcer & 04 & 04 \\
Diabetic muscular infarction & 02 & 02 \\
Diabetic amyotrophy & 02 & 02 \\
\hline
\end{tabular}

Table $\mathbf{1 . 5}$

Association of stroke, IHD, obesity $(n=100)$

\begin{tabular}{lcc}
\hline Association & $\begin{array}{c}\text { Number of } \\
\text { patient }\end{array}$ & $\begin{array}{c}\text { Percentage } \\
(\%)\end{array}$ \\
\hline Stroke & 72 & 72 \\
Ischaemic heart disease & 20 & 20 \\
Obesity & 08 & 08 \\
\hline
\end{tabular}

$\mathrm{n}$ : number of patient 
Table 1.5 Shows that $72 \%$ of patient had history of Stroke, $72 \%$ Ischaemic heart disease 20\% \& Obesity 08\%.

Table 1.6

Economic status of the patients $(n=100)$

\begin{tabular}{lcc}
\hline $\begin{array}{l}\text { Economic } \\
\text { status }\end{array}$ & $\begin{array}{c}\text { Number of } \\
\text { patients }\end{array}$ & $\begin{array}{c}\text { Percentage } \\
(\%)\end{array}$ \\
\hline $\begin{array}{l}\text { Low (Less than Tk. } \\
\text { 60,000/=per annum) }\end{array}$ & 66 & 66 \\
$\begin{array}{l}\text { Middle (From Tk. } \\
\text { 60,000 - Tk. 1,80,000/ }\end{array}$ & 26 & 26 \\
=per annum) & & \\
High ( > Tk. 180,000) & 8 & 8 \\
\hline Total & 100 & $100 \%$ \\
\hline
\end{tabular}

$\mathrm{n}$ : number of patients, this income status classification was according to Bangladesh Bureau of Statistics.

Table 1.6 shows that the low income group $(63 \%)$ comprises the major percentage of the patients, which was followed by middle income group (33\%).

\section{Discussion:}

A large number of systemic conditions have NM manifestations. Neuromuscular complaints (NMCs) are among the major health problems worldwide and the most frequent cause of long-term sickness leave in Norway ${ }^{10,11}$. The present study has observed that sensory polyneuropathy and motor polyneuropathy are common and are more frequently seen in diabetic clinic. Moreover, sensory polyneuropathy and motor polyneuropathy was strongly associated with type $2 \mathrm{DM}$ whereas autonomic neuropathy and neuropathic ulcer was associated with Type 1 DM. The limitation of this study is that some of the association or lack of association is due to referral bias. Despite these limitations, there is little doubt that certain neuromuscular complaints (NMCs) are seen more frequently in diabetics than otherwise.DM may affect the neuromuscular system in a variety of ways. Neuromuscular complications are most commonly seen in patients with a longstanding history of type 1 diabetes, but they are also seen in patients with type 2 diabetes. Some of the complications have a known direct association with diabetes, whereas others have a suggested but unproven association. Effective management requires detailed medical history, relevant physical examination. Laboratory tests aids little in management, particularly in patients of developing country like Bangladesh.

In our study, the general objective was to find out the common patterns of NMM in patients with DM. We enrolled 100 diagnosed cases of DM with neuromuscular manifestations, both men and women (aged e"15-70 years) who were admitted in the medicine ward of Dhaka Medical College Hospital fulfilling the inclusion criteria. Out of consecutive 100 patients in my study, $72(72 \%)$ were Male and 28(28\%) were female giving male -female ratio 2.57:1. Age distribution of study patients were 14 to 70 years. Maximum numbers of the patients were in the age group of 40 to 59 years $(72 \%)$. Out of 100 patients, we enrolled 94 patients with Types 2 DM(on drugs) \& only 06 patients with Types 1 DM (on insulin) .Occupation of the patients with neuromuscular manifestations showed majority patients were housewife $(28 \%)$. Other was business $(14 \%)$, Service $(16 \%)$.Unemployed $(20 \%)$ and cultivator $(14 \%)$. Individual NM abnormalities in patients with DM showed majority patients had sensory polyneuropathy $48 \%$, Motor polyneuropathy $20 \%$, mononeuropathy $18 \%$. Others had autonomic neuropathy 06\%.Association of stroke, IHD, obesity \& NMM abnormalities in patients with DM were seen \&it revealed majority patients (72\%) had Stroke, $20 \%$ had Ischaemic heart disease \& Obesity in $08 \%$ of patients. Economic status of the patients showed that low income group (63\%) comprises the major percentage, which was followed by middle income group (33\%). Sarkar et al in a cross sectional study the compared neurological, muscular and rheumatic manifestations in a cohort of diabetic patients with a group of patients attending a rheumatology clinic of a medical college. Ideally, one would have compared between the diabetics and age, sex and body mass index matched healthy population to attribute if any of the manifestations are associated with diabetes mellitus. Some studies have indeed compared the prevalence of certain 
manifestations in diabetics such as diabetic muscular infarction and diabetic amyotrophy and reflex sympathetic dystrophy with that of rheumatic controls ${ }^{8,25}$.

\section{Conclusion:}

Considering the information gathered from the study, it can be concluded that NMMs in patient with DM are much more problematic among diabetics. From the present study it may be said that the most common conditionof NMM in patient with DM is sensory polyneuropathy.

\section{Limitations of the study:}

- aaonstraint.

\section{References:}

1. Cagliero E, Apruzzese W, Perlmutter GS, Nathan DM. Musculoskeletal disorders of the hand and shoulder in patients with diabetes mellitus. Am J Med 2002;112:487.

2. Burner, Todd, Rosenthal, Ann K. Diabetes and rheumatic diseases. Curr Opin Rheumatol 2009; 21(1):50-4

3. Grey A, Dalbeth N. Bone and rheumatic disorders in diabetes. 48:749.

4. Arkkila P, Gautier JF. Musculoskeletal disorders in diabetes mellitus: an update. Best Pract Res Clin Rheumatol 2003;17(6):945-70.

5. Smith LL, Burnet SP, McNeil JD. Musculoskeletal manifestations of diabetes mellitus. $\mathrm{Br} \mathrm{J}$ Sports Med 2003; 37: 30-5

6. The effect of intensive treatment of diabetes on the development and progression of long-term complications in insulin-dependent diabetes mellitus. The Diabetes Control and Complications Trial Research Group. N Engl J Med 1993; 329: 977-86.

7. Kapoor A., Sibbitt Jr. W.L. Contractures in diabetes mellitus: The syndrome of limited joint mobility. Semin Arthritis Rheum 1989;18:168.

8. Sarkar RN, Banerjee S, Basu AK, Bandyopadhyay. Rheumatological manifestations of diabetes mellitus. J Ind Rheumatol Assoc 2003;11:25-9.

9. Kiss C, Szilágyi M, Paksy A, Poór G. Risk factors for diffuse idiopathic skeletal hyperostosis: a casecontrol study. Rheumatology 2002;41:27-30.

10. The burden of musculoskeletal conditions at the start of the new millennium. World Health Organ Tech Rep Ser Volume 919. Geneva, Switzerland: World Health Organization; 2003: p.1-218.

11. Statistics of sick leave in Norway in 2007 [http:/ /www.nav.no]

12. Andersson HI. The course of non-malignant chronic pain: a 12- year follow-up of a cohort from the general population. Eur J Pain 2004;8: 47-53

13. Haslock I. Common periarticular syndromes. Med Intern 1914;7:173-6
14. Joslin EO, Root EF, White P. The treatment of diabetes mellitus. Philadelphia: Lea \& Febiger; 1959.

15. L L Smith, S P Burnet, J D McNeil. Br J Sports Med 2003; 37:30-5.

16. Crispin JC, Alcocer-Valera J. Rheumatic manifestations of diabetes mellitus. Am J Med 2003;14(9):753-7.

17. Makita Z, Radoff S, Rayfield EJ. Advanced glycosylation end products in patients with diabetic nephropathy. New Engl J Med 1991;325:836-42.

18. Gamstedt A. Hand abnormalities in patients with NIDDM. Prog Diabetes 1993;4:1-6

19. Rachel Peterson Kim, MD; Steven V. Edelman, MD; and Dennis D. Kim, MD. Volume 19, : Clin Dia Number 3, 2001:

20. Buckingham BA, Uitto J, Sandborg C, et al. Scleroderma-like changes in insulin-dependent diabetes mellitus: clinical and biochemical studies. Diabetes Care 1984;7:163-9.

21. Jennings AM, Milner PC, Ward JD. Hand abnormalities are associated with the complications of diabetes in type 2 diabetes. Diabet Med 1989;6:43-7.

22. Starkman HS, Gleason RE, Rand LI, et al. Limited joint mobility (LJM) of the hand in patients with diabetes mellitus: relation to chronic complications. Ann Rheum Dis 1986;45:130-5.

23. Reeves B. The natural history of the frozen shoulder syndrome. Scand J Rheumatol 1975;4:193-6.

24. Forgács SS. Endocrine and hemoglobin arthropathies: diabetes mellitus. In: Rheumatology. London: Mosby-Year Book Europe Ltd; 1994.

25. Griggs SM, Ahn A, Green A. Idiopathic adhesive capsulitis. A prospective functional outcome study of nonoperative treatment. J Bone Joint Surg [Am] 2000;82:1398-407.

26. Bridgman JF. Periarthritis of the shoulder and diabetes mellitus. Ann Rheum Dis 1972;31: 69-71.

27. Lequesne $\mathrm{M}$, Dang $\mathrm{N}$, Bensasson $\mathrm{M}$, et al. Increased association of diabetes mellitus with capsulitis of the shoulder and shoulder-hand syndrome. Scand J Rheumatol 1977;6:53-6

28. Balci N, Balci MK, Tuzuner S. Shoulder adhesive capsulitis and shoulder range of motion in type II diabetes mellitus: association with diabetic complications. J Diabetes Complications 1999; 13:135-40

29. Arkkila PE, Kantola IM, Viikari JS, et al. Shoulder capsulitis in type I and II diabetic patients: association with diabetic complications and related diseases. Ann Rheum Dis 1996;55: 907-14.

30. Noble J, Heathcote JG, Cohen H. Diabetes mellitus in the aetiology of Dupuytren's disease. J Bone Joint Surg [Br] 1984;66:322-5. 